\title{
Comparison of Some Pretreatment Methods on Cellulose Recovery from Water Hyacinth (Eichhornia Crassipe)
}

\author{
Bich Thuyen Nguyen Thi, Luong H. V. Thanh, T. N. Phuong Lan, N. T. Dieu Thuy, and Yi-Hsu Ju
}

\begin{abstract}
The effects of three physical pretreatment methods (water bath, ultrasound and microwave) on the cellulose recovery of water hyacinth were investigated in this study. Before treatment, cellulose and hemicellulose content of dried water hyacinth sample was $\mathbf{3 6 . 0 4 \%}$. After treating by ultrasound $\left(7^{\circ} \mathrm{C}\right.$ for $1 \mathrm{~h}$ ) at a ratio of deionized water (DIW) $(\mathrm{mL})$ to dried sample $(\mathrm{g})$ of 10:1, cellulose and hemicellulose content in the treated sample was $57.7 \pm 0.65 \%$. The highest yield of cellulose and hemicellulose $(58.19 \pm 0.59 \%)$ obtained by water bath treament at $100^{\circ} \mathrm{C}$ for $1 \mathrm{~h}$ whereas the cellulose and hemicellulose yield was $60.42 \pm 0.07 \%$ attained by microwave pretreatment $(350 \mathrm{~W}, 10 \mathrm{~min}$ at a ratio of DIW $(\mathrm{mL})$ to dried sample (g) of 10:1). Therefore, among three pretreatment methods, microwave assisted DIW pretreatment presented the best efficiency on cellulose recovery. The outcome showed that microwave assisted DIW pretreated water hyacinth is a promising raw material for bioethanol production. The effects of these treatments on the composition and structure of water hyacinth were studied by thermogravimetric analysis (TGA), Fourier transform infrared spectroscopy (FTIR) and scanning electron microscopy (SEM).
\end{abstract}

Index Terms-Water hyacinth, Eichhornia crassipes, cellulose recovery, ultrasound, microwave and water bath.

\section{INTRODUCTION}

Water hyacinth (Eichhornia crassipes) is a widespread aquatic weed in tropical or subtropical areas. In most countries, water hyacinth is recognized as a big threat to agriculture and aquatic ecosystem because of its rapid growth rate [1]. Xia et al. (2013) believed that water hyacinth is one of the top 10 worst weeds in the world. This aquatic plant causes serious environmental pollution and great economic losses. A single plant of water hyacinth can have 140 million daughter plants annually, this amount is enough to cover an area of $1.40 \mathrm{~km}^{2}$ with a fresh biomass of 28,000 tons. This invasive plant has deteriorated native ecosystems, clogged up lakes and rivers [2]. However, water hyacinth has high cellulose and hemicellulose contents (Table I) which can provide sugars for bioconversion to fuel ethanol [1]-[10].

In the last few decades, fossil fuel sources have been exhausted, therefore, finding replaced sources is a pressing mission. The first generation sources are sugar or starch based on crops [3]. However, this has conflict with food supply [11].

Manuscript received November 9, 2015; revised May 19, 2016.

Bich Thuyen Nguyen Thi and Yi-Hsu Ju are with National Taiwan University of Science and Technology, Department of Chemical Engineering, 43 Sec.4, Keelung Rd., Taipei, 10607, Taiwan, R.O.C (e-mail: ntbthuyen@ctu.edu.vn,yhju@mail.ntust.edu.tw).

Luong H. V. Thanh, T. N. Phuong Lan, and N. T. Dieu Thuy are with Can Tho University, Vietnam (e-mail: lhvthanh@ctu.edu.vn, tnplan@ctu.edu.vn).
Therefore, lignocellulosic materials (second generation) are gradually considered as more attractive renewable resources for fuel production owing to their easy availability and relatively low cost [3] and [11]. Many researches [5]-[7], [10] have investigated ethanol production from water hyacinth. Bioethanol production from wheat straw has been reported by Singh \& Bishnoi (2013) and Guragain et al. (2011). Ahmed (2013) studied ethanol production from Melalueca leucadenderon. In that year, Gao et al. (2013) produced hydrochar from water hyacinth. Hydrogen and methane were generated from water hyacinth [4]. Study on saccharification techniques of seaweed wastes for the production of ethanol was carried out by Ge et al. (2011). Besides, in order to utilize waste resources, Subhedar \& Gogate (2015) reported the production of ethanol from waste newspaper. Ethanol was produced using potato peel as feedstock [12].

The objective of these researches was fuel conversion from lignocellulosic materials. However, there are many barriers because many steps are required. First step is pretreatment of biomass to break down lignin-hemicelluloses-cellulose complex to make it more susceptible to hydrolysis. The second step is hydrolysis to break down cellulose and hemicellulose into sugar monomers; and the third step is fermentation of these sugars to ethanol. The final step is product recovery and concentration by distillation [6], [13]. Among these steps, pretreatment is a major challenge because of structural linkages in lignocellulose, which are difficult to break at normal conditions [1]. Therefore, pretreatment is essential to remove biomass lignin, which hinders hydrolysis reaction [14].

Pretreatments include physical, chemical, biological, and combination of these methods [1], [15]. Physical pretreatment changes biomass structure by applying mechanical shear, without adding chemical or biological reagent [1].

This study aimed at investigating the effects of various physical pretreatment methods (ultrasound, microwave and water bath) on cellulose recovery and delignification of water hyacinth.

\section{MATERIALS AND METHODS}

Fresh Eichhornia crassipe plants used in this study were harvested from Hau river, Viet Nam. The dried sample was ground and screened through $0.7 \mathrm{~mm}$ wire-mesh sieve. The sample was either used immediately or stored in airtight plastic bags at $4^{\circ} \mathrm{C}$ until used.

In order to compare the efficiency between pretreatment methods on cellulose recovery, the best pretreatment condition of each method was firstly selected based on cellulose yield and reducing sugars of the pretreated sample. 
Thermalgravimetric analysis (TGA), Fourier transform infrared spectroscopy (FTIR) and scanning electron microscopy (SEM) were used for examining the composition and structure of the treated samples.

TABLE I: LIGNOCELLULOSIC CONTENT OF WATER HYACINTH (\% DRY BIOMASS)

\begin{tabular}{|c|c|c|c|c|}
\hline Cellulose & Hemicellulose & Lignin & References & Treatment methods \\
\hline 18.3 & 23.3 & 17.7 & [9] & untreated \\
\hline \multirow[t]{6}{*}{24.3} & 22.5 & 8.6 & [9] & DMSO, $120^{\circ} \mathrm{C}, 24 \mathrm{~h}$ \\
\hline & 36 & 6.5 & [1] & untreated \\
\hline & 49 & not shown & [1] & ultrasound, $20 \mathrm{~min}$ \\
\hline & 36.04 & 2.51 & this study & untreated \\
\hline & 58.19 & 1.37 & this study & water bath, DIW, $100^{\circ} \mathrm{C}, 1 \mathrm{~h}$ \\
\hline & 60.42 & 0.63 & this study & microwave, DIW, $350 \mathrm{~W}, 10 \mathrm{~min}$ \\
\hline
\end{tabular}

\section{A. Water Bath Pretreatment}

Dried sample (1g) was mixed with deionized water (DIW) and incubated in a water bath. The conditions in this experiment were as follows: ratio of DIW $(\mathrm{mL})$ to dry biomass $(\mathrm{g})$ of $7: 1 ; 10: 1 ; 15: 1$ or $20: 1$, treatment time of 30 , 60,90 or $120 \mathrm{~min}$ and treatment temperature of 70,80 or $100^{\circ} \mathrm{C}$.

\section{B. Ultrasound Pretreatment}

An ultrasonic bath was used in this trial (model SB-5200 DTN; temperature control range: room temperature (RT) $-70^{\circ} \mathrm{C}$; frequency $\left.(\mathrm{kHz}): 10\right)$. The experiment was conducted at a ratio of DIW $(\mathrm{mL})$ to dry biomass $(\mathrm{g})$ of $7: 1 ; 10: 1 ; 15: 1$ or $20: 1$ and treatment time of $15,30,60$ or $90 \mathrm{~min}$. The bath was operated at $70^{\circ} \mathrm{C}, 25 \mathrm{kHz}$ and a maximum power of $200 \mathrm{~W}$.

\section{Microwave Pretreatment}

Microwave - assisted pretreatment on dried water hyacinth was carried out in microwave oven (Tatung, model TMO-7D-BK, power consumption: $120 \mathrm{~V} \sim 60 \mathrm{~Hz}, 1200 \mathrm{~W}$, operation frequency: $2,450 \mathrm{MHz} ; 30$ minute timer).

The experiment was carried out at various times $(5,10,15$, 20 and $30 \mathrm{~min}$ ) and various ratio of DIW (mL) to dry biomass (g) of $7: 1 ; 10: 1 ; 15: 1$ or $20: 1$, respectively.

After pretreatments, the solid was collected by filtration and washed by DIW. The dried solid was analyzed for its lignocellulosic content by TGA. Reducing sugar compositions in the liquid were analyzed by DNS (3,5-dinitrosalicylic acid) method [16]. Each experiment was done at least in duplicates.

\section{Thermal Analysis}

Dried water hyacinth sample (5-7 mg) was pyrolyzed by a TGA (Model : Perkin Elmer, temperature range: $30-800^{\circ} \mathrm{C}$ ). The increasing rate of temperature was $10^{\circ} \mathrm{C} / \mathrm{min}$. Nitrogen atmosphere $(40 \mathrm{~mL} / \mathrm{min})$ was employed in this experiment.

\section{E. Fourier Transform Infrared Spectroscopy (FTIR)}

A FTIR Bio-Rad FTS-3500 spectroscopy was employed to determine the alteration of chemical component of the treated sample. The spectrum was obtained in the transmission mode and wave number range of $4000-400 \mathrm{~cm}^{-1}$ at a resolution of 4 $\mathrm{cm}^{-1}$ with 40 scans per sample.

\section{F. Scanning Electron Microscopy (SEM)}

Surface morphology of the sample was observed by a scanning electron microscopy (SEM, JSM-6390LV, JEOL, Japan) at an accelerated voltage of $15-20 \mathrm{kV}$ after gold or platinum coating by a JEOL JFC-1100 E sputtering device for 85 seconds prior to SEM observation.

\section{RESULTS AND DISCUSSION}

\section{A. Effect of DIW to Dried Sample Ratio on Reducing Sugar Content}
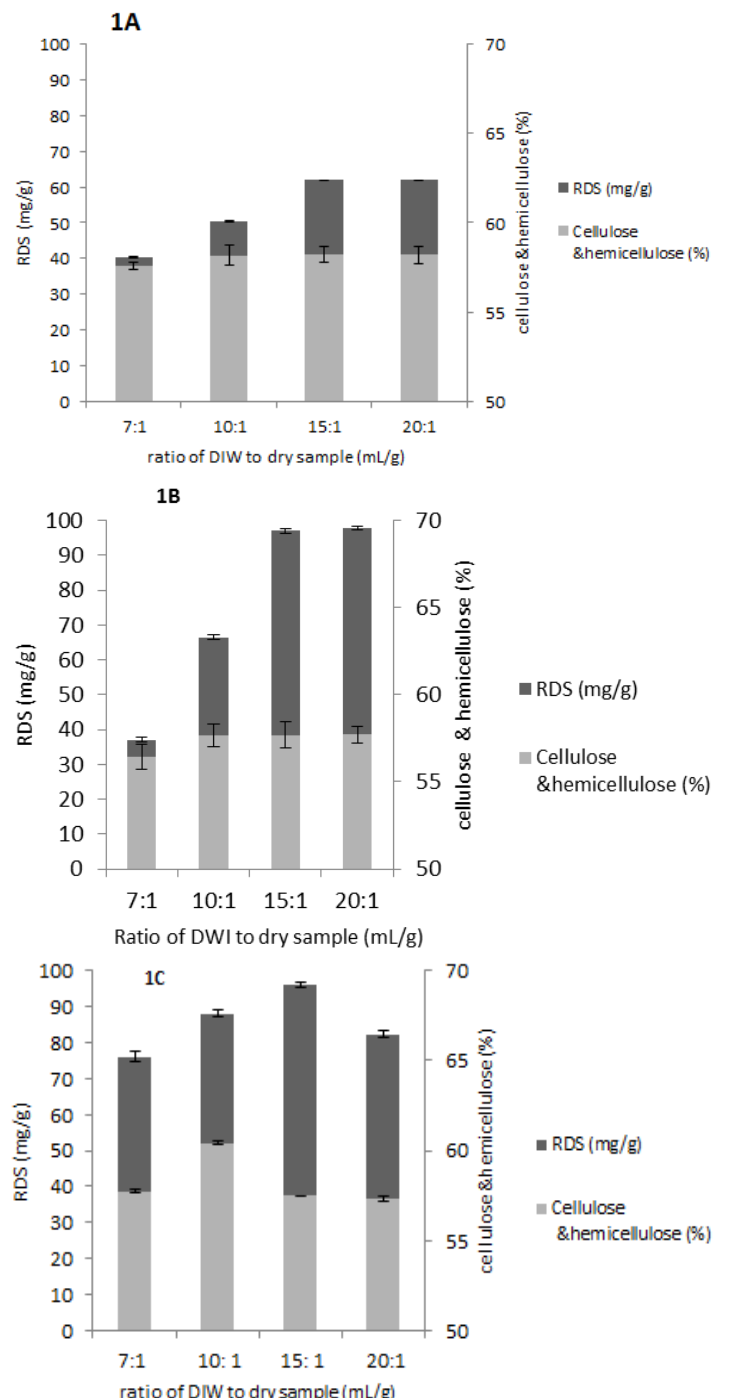

Fig. 1. Effect of DIW to dried sample ratio $(\mathrm{mL} / \mathrm{g})$ on the lignocellulose and reducing sugar yield of water hyacinth attained from: (1A) water bath pretreatment (at $100^{\circ} \mathrm{C}, 60 \mathrm{~min}$ ); (1B) ultrasound pretreatment (at $70^{\circ} \mathrm{C}, 60$ $\mathrm{min}$ ); (1C) microwave pretreatment (at $350 \mathrm{~W}, 10 \mathrm{~min}$ ).

For water bath pretreatment, Fig. 1A shows that reducing sugar yield increased from $40.31 \mathrm{mg} / \mathrm{g}$ to $61.93 \mathrm{mg} / \mathrm{g}$ as DIW to dried biomass ratio was changed from $7: 1$ to $15: 1 \mathrm{~mL} / \mathrm{g}$. This may be attributed to the role of water in the degradation of lignocellulosic materials leading to releasing of sugars from biomass matrix. More water resulted in higher penetration. A ratio of 7:1 of DIW to dried biomass was not 
enough water to solubilize carbohydrates leading to low sugar release after a week digestion. The increase of DIW to dried biomass ratio to $15: 1 \mathrm{~mL} / \mathrm{g}$ resulted in high yield of sugars $(61.93 \mathrm{mg} / \mathrm{g})$. However, increasing the ratio of DIW to dried sample to $20: 1 \mathrm{~mL} / \mathrm{g}$ did not increase reducing sugar yield, which $61.98 \mathrm{mg} / \mathrm{g}$. Similar phenomena were observed in the ultrasound pretreatment (Fig. 1B). In contrast, in microwave-assisted pretreatment, sugars content was decreased from $96.08 \mathrm{mg} / \mathrm{g}$ to $82.33 \mathrm{mg} / \mathrm{g}$ as the ratio of DIW to dried biomass was increased from $15: 1$ to $20: 1 \mathrm{~mL} / \mathrm{g}$ (Fig. 1C). This is because unlike conventional heating, microwave irradiation directly and quickly permeated into the inner particles to selectively heat sensitive polar molecules, such as water [2]. Microwave oscillation caused polar water molecules to collide with each other, thereby generating a large amount of heat to effectively break lignocellulose materials and crystal structures [2]. Therefore, more water leads to more generated heat leading to degradation of sugars into smaller molecular such as acetic acid, furfural or hydroxyl methyl furfural (HMF) [2].

\section{B. Effect of DIW to Dried Sample Ratio on Lignocellulose Content}

Fig. $1 \mathrm{~A}$ shows that water bath treatment at $100^{\circ} \mathrm{C}$ for $1 \mathrm{~h}$ dramatically decomposed lignin compounds in biomass matrices. Untreated water hyacinth contains $2.51 \%$ lignin, $36.04 \%$ cellulose and hemicellulsose. After pretreatment using a ratio of DIW to dried sample $7: 1 \mathrm{~mL} / \mathrm{g}$, cellulose and hemicellulose content in residue solid was $57.59 \%$, with a corresponding lignin content of $1.43 \%$. Cellulose and hemicellulose content inreased to $58.19 \%$ when the ratio of DIW to biomass was increased to $10: 1 \mathrm{~mL} / \mathrm{g}$. The reason was that at this ratio (10:1), lignin content in the residue was $1.37 \%$ which means that better lignin removal than at a ratio of $7: 1(1.43 \%)$ leading to expelling of cellulose and hemicellulose from matrices. However, cellulose and hemicellulose content remained almost constant though DIW to dried biomass ratio was increased from 10:1 to $20: 1$ because while cellulose and hemicellulose were generated by pretreatment, they were subsequently converted to sugars including glucose, xylose, galactose or arabinose [1], [2], [4], [6], [7], [9], [14], [17]; hence the productivity of sugars increased as DIW to dried biomass ratio was increased from 10:1 to 20:1 (Fig. 1A). This observation was also found in ultrasound pretreatment (Fig. 1B). The highest yield of cellulose and hemicellulose in solid residue $(57.70 \%)$ was obtained at a DIW to dried biomass ratio of $10: 1,70^{\circ} \mathrm{C}$ and 1 $\mathrm{h}$. This value stabilized even as DIW to biomass ratio was increased from 10:1 to 20:1.

Water bath pretreatment degrades lignocellulosic materials by conventional heating while ultrasound decomposes the materials by formation and explosion of bubbles [18]. Unlike these two methods, microwave irradiation digests biomass by electromagnetic wave [2] which generates energy by collisions of polar molecules like water. Therefore, increasing DIW to biomass ratio from 10:1 to $20: 1$ produced more energy, leading to degradation of cellulose and hemicellulose to sugars. Therefore, cellulose and hemicellulose content dropped form $60.42 \%$ to $57.30 \%$ (Fig. 1C).

For calculating a theoretical maximum reducing sugar yield.
It was assumed that cellulose and hemicellulose in water hyacinth completely hydrolyze into hexose (viz. glucose) and pentose (viz. xylose). The weight ratio of glucose molecule to cellulose was 1.111 and that of xylose to hemicellulose was 1.136. Given that the water hyacinth sample contained $36.04 \%$ cellulose and hemicellulose, the theoretical maximum glucose and xylose hydrolyze that can be originated from $100 \mathrm{~g}$ of the sample were $40.49 \mathrm{~g} / 100 \mathrm{~g}$ biomass [2].

In this study the highest reducing sugars yield obtained was $96.08 \mathrm{mg} / \mathrm{g}$ which was only $23.70 \%$ of the theoretical value whereas the highest cellulose and hemicellulose recovery after treatment was $60.42 \%$, which is $134.18 \%$ of the untreated sample. Therefore, further experiments were based on the optimal conditions for cellulose and hemicellulose recovery.

\section{Effect of Time on Reducing Sugar Content}

The effect of treatment time on reducing sugar and lignocellulose content was conducted based on the optimal conditions for cellulose and hemicellulose recovery in Section III.A.
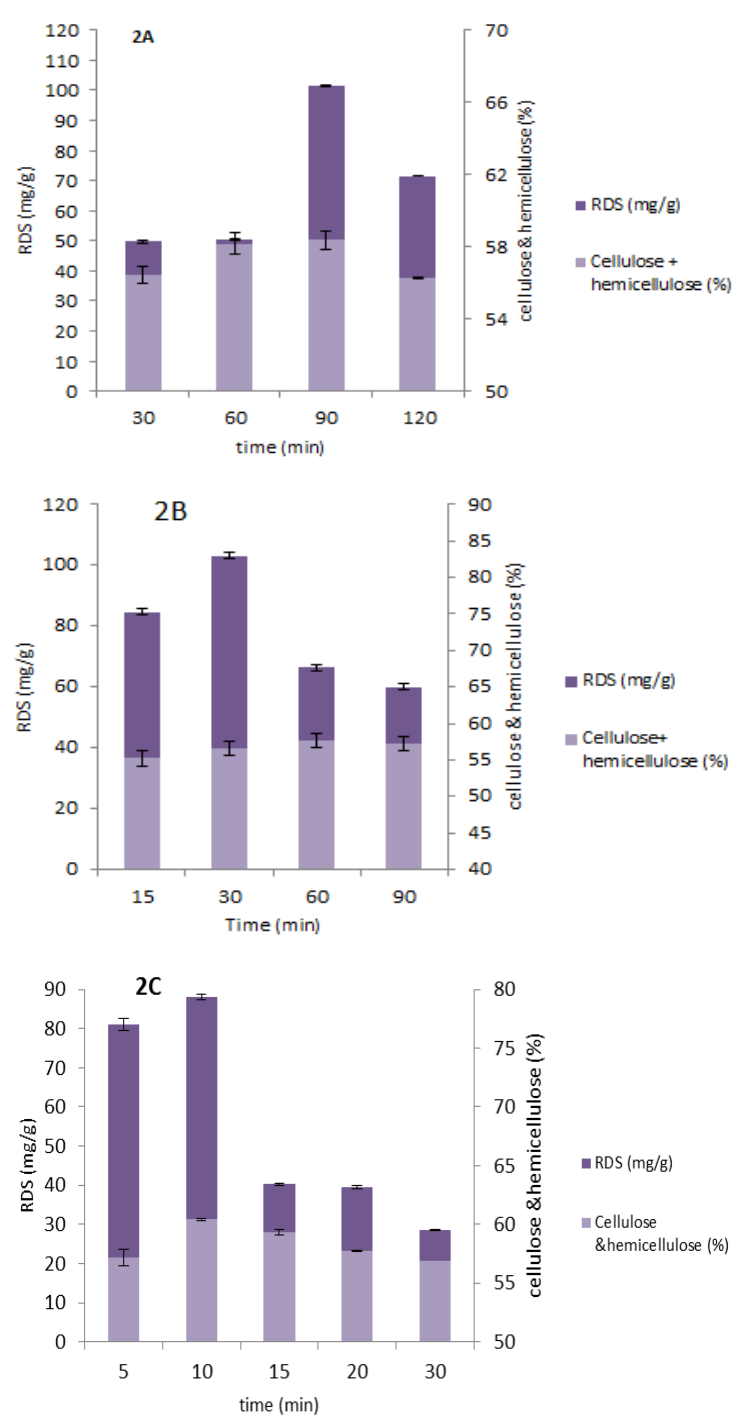

Fig. 2. Effect of time on the lignocellulose and reducing sugar yield of water hyacinth attained from: $(2 \mathrm{~A})$ water bath pretreatment at $100^{\circ} \mathrm{C}, \mathrm{DIW}(\mathrm{mL})$ to dried sample $(\mathrm{g})$ ratio of $10: 1 ;(2 \mathrm{~B})$ ultrasound pretreatment at $70^{\circ} \mathrm{C}$, DIW $(\mathrm{mL})$ to dried sample $(\mathrm{g})$ ratio of $10: 1$; (2C) microwave pretreatment at $350 \mathrm{~W}$, DIW $(\mathrm{mL})$ to dried sample $(\mathrm{g})$ ratio of 10:1. 
Similar trend was found on the effect of time on reducing sugar and lignocellulose content for all three pretreatment methods. Prolonging reaction time resulted in decreasing sugars as well as cellulose and hemicellulose contents because of degradation of these compounds to smaller molecular.

For ultrasound pretreatment (Fig. 2B), 30 min treatment time gave the highest amount of reducing sugar $(103.04 \mathrm{mg} / \mathrm{g})$ which was only $25.44 \%$ of the theoretical value. An increase of time to $60 \mathrm{~min}$ resulted in decreasing reducing sugar content sharply to $66.46 \mathrm{mg} / \mathrm{g}$ since sugars continued to decompose to smaller molecular such as formic acid, pentanoic acid, acetic acid, furfural or hydroxyl methyl furfural (HMF) and propiolic acid [2]. Treatment by water bath generated the highest reducing sugars at $90 \mathrm{~min}$ (101.57 $\mathrm{mg} / \mathrm{g}$ ) and this value tumbled to $71.53 \mathrm{mg} / \mathrm{g}$ when time was raised to $120 \mathrm{~min}$ (Fig. 2A). For microwave-assisted treatment, reducing sugars content dropped considerably from $88.15 \mathrm{mg} / \mathrm{g}$ to $28.56 \mathrm{mg} / \mathrm{g}$ as treatment time was increased from $10 \mathrm{~min}$ to $30 \mathrm{~min}$ (Fig. 2C).

The finding of this study agrees with the results of Harun $e t$ al. (2011) who reported that increasing steaming time of water hyacinth from $30 \mathrm{~min}$ to $90 \mathrm{~min}$ decreased reducing sugars from $37.62 \mathrm{mg} / \mathrm{g}$ to $22.74 \mathrm{mg} / \mathrm{g}$. In the same study, the authors showed that reducing sugars dropped from 116.52 $\mathrm{mg} / \mathrm{g}$ to $97.25 \mathrm{mg} / \mathrm{g}$ as ultrasonication time was increased from $20 \mathrm{~min}$ to $30 \mathrm{~min}$ [1]. Xia et al. (2013) evidenced that reducing sugars of water hyacinth declined due to producing of furfural, 5-methyl-2-furaldehyde, and 5-hydroxymethyl2-furaldehyde, formic acid, 2-methylpropanal and propiolic acid as microwave irradiation time was prolonged from 15 $\min$ to $45 \min$ [2].

\section{Effect of Time on Lignocellulose Content}

For ultrasonication pretreatment (Fig. 2B), maximal yield of cellulose and hemicellulose was obtained at $60 \mathrm{~min}$ $(57.70 \%)$. Prolonging of time to $90 \mathrm{~min}$ did not improve cellulose and hemicellulose yield because cellulose was converted to hexoses (glucose, galactose) and hemicellulose produced glucose and pentoses such as xylose, arabinose [1], [2], [4], [6], [7], [9], [13], [14].

The maximum cellulose and hemicellulose content $(58.37 \%)$ was obtained at $90 \mathrm{~min}$ for water bath treatment and $60.42 \%$ at 10 min from microwave irradiation, corresponding to $1.38 \%$ and $0.63 \%$ lignin yield, respectively. For water bath pretreatment, increasing reaction time from $90 \mathrm{~min}$ to $120 \mathrm{~min}$ decreased lignin content from $1.38 \%$ to $1.28 \%$, but cellulose and hemicellulose content also dropped from $58.37 \%$ to $56.29 \%$ because of cellulose and hemicellulose digestion to sugars (Fig. 2A). This finding was observed similarly in microwave pretreatment where the removal of lignin at 10 min was $0.63 \%$ and this value decreased to $0.62 \%$ as time was lengthened to $15 \mathrm{~min}$ but cellulose and hemicellulose content did not increase with increasing time after $10 \mathrm{~min}$ (Fig. 2C).

This observation agrees with that of Xia et al. (2013) [2] who believed that prolonged microwave irradiation time of water hyacinth from $5 \mathrm{~min}$ to $45 \mathrm{~min}$ resulted in decreasing weight percentages of residual solid biomass $(46.20 \%-36.85 \%)$, residual hemicellulose $(25.25 \%-0 \%$; complete degradation), residual cellulose $(83.48 \%-62.67 \%)$, and lignin $(89.86 \%-60.75 \%)$.

\section{E. Effect of Temperature on Reducing Sugar and Lignocellulose Content}

For water bath pretreatment, the experiments investigated at $70^{\circ} \mathrm{C}, 80^{\circ} \mathrm{C}$ and $100^{\circ} \mathrm{C}$. Treating at lower than $100^{\circ} \mathrm{C}$ (in 60 min and a ratio of DIW (mL) to dried biomass ( $\mathrm{g}$ ) of 10:1) did not give satisfactory yields of reducing sugars, cellulose and hemicellulose because apparently temperatures lower than $100^{\circ} \mathrm{C}$ did not supply enough heat to digest the sample.

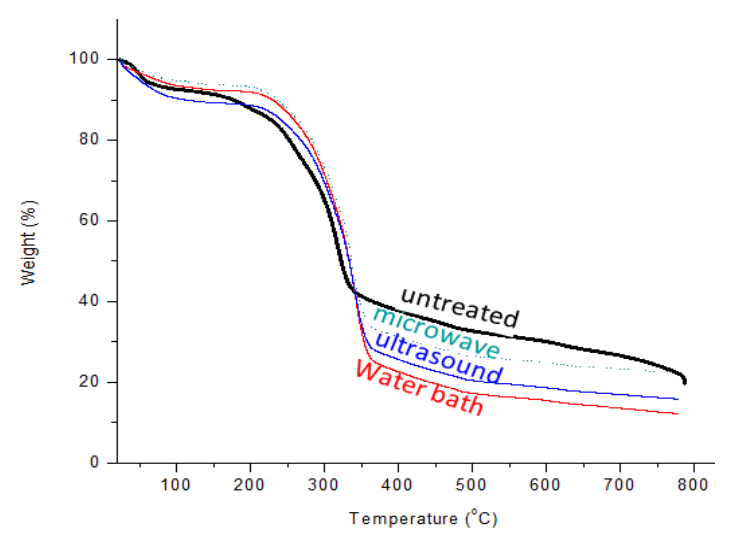

Fig. 3. TGA curves of water hyacinth.

Ultrasonication technique usually is used at low temperature (ambient to $70^{\circ} \mathrm{C}$ ). This method breaks material's contents mainly based on formation and explosion of bubbles. In this study, treating sample at $60^{\circ} \mathrm{C}$ did not give satisfactory results.

For microwave treatment, the highest yields of reducing sugar, cellulose and hemicellulose were obtained at $350 \mathrm{~W}$ for 10 min with a DIW to dried sample ratio of $10: 1(\mathrm{~mL} / \mathrm{g})$. Treatment at $450 \mathrm{~W}$ decreased dramatically the productivity since the sample was burn at high power (data not shown).

Briefly, the optimal conditions for cellulose and hemicellulose recovery in this study were found at DIW to dried biomass ratio of $10: 1(\mathrm{~mL} / \mathrm{g})$ for all three pretreatments; the temperature of $100^{\circ} \mathrm{C}, 60 \mathrm{~min}$ and for water bath pretreatment; $70^{\circ} \mathrm{C}, 60 \mathrm{~min}$ for ultrasound pretreatment and $350 \mathrm{~W}, 10 \mathrm{~min}$ for microwave irradiation.

Among the three studied pretreatment methods, microwave assisted DIW pretreatment seems to be the best method for cellulose and hemicellulose recovery from water hyacinth.

\section{F. Thermal Analysis}

Hemicellulose and cellulose are decomposed at $200-350^{\circ} \mathrm{C}$, lignin decomposition occurs at $350-470^{\circ} \mathrm{C}$ [1]. Fig. 3 indicates that hemicellulose was digested at $265^{\circ} \mathrm{C}$ while the main peak that appeares at $326^{\circ} \mathrm{C}$ was attributed to cellulose degradation. However, almost all sample curves show that hemicellulose peak is the only shoulder in the derivative thermogravimetric curve which means hemicellulose was the minor component in water hyacinth. The small peak appeared at approximately $468^{\circ} \mathrm{C}$ was contributed to lignin. This observation agrees with that of Harun, 2011.

\section{G. Scanning Electron Microscopy (SEM)}

Fig. 4A shows that the untreated sample's surface was still smooth and tightly random. The structure was changed after 
treating by ultrasonic wave irradiation at $70^{\circ} \mathrm{C}$ for $1 \mathrm{~h}$. As seen from Fig. 4B, broken structure was observed due to the applied ultrasonic waves that generated micro bubbles which exploded eventually and caused the sample to break down leading to releasing of cellulose and hemicellulose form matrices. For this reason, cellulose and hemicellulose content in the treated sample was higher than that of the non-treated one. This was also observed in water bath pretreatment at $100^{\circ} \mathrm{C}$ for $1 \mathrm{~h}$ which shows that cracked ditch appeared in the treated sample (Fig. 4C). For the microwave-treated sample, the surface of water hyacinth became crumbled. This finding indicates that the intact structure of lignocellulose was dramatically ruined and cellulose was completely expelled by microwave pretreatment (Fig. 4D). Thus, the yield of cellulose, hemicellulose and reducing sugar was improved compared to other pretreatments.

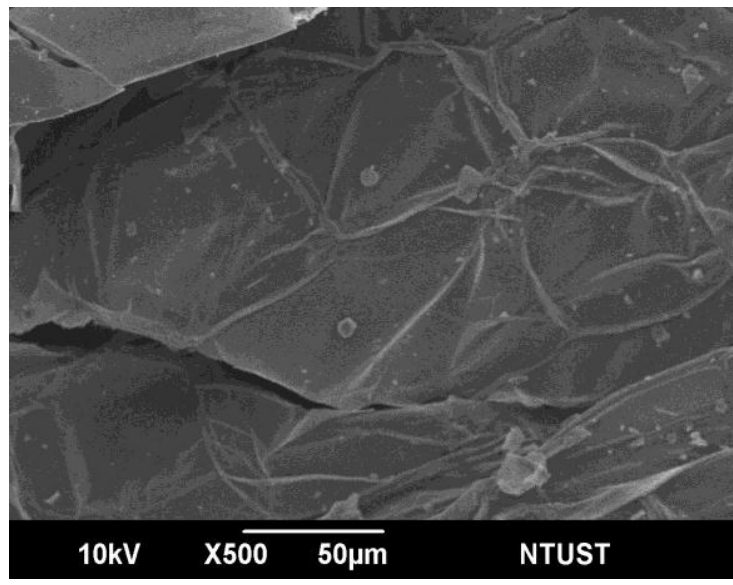

$(4 \mathrm{~A})$

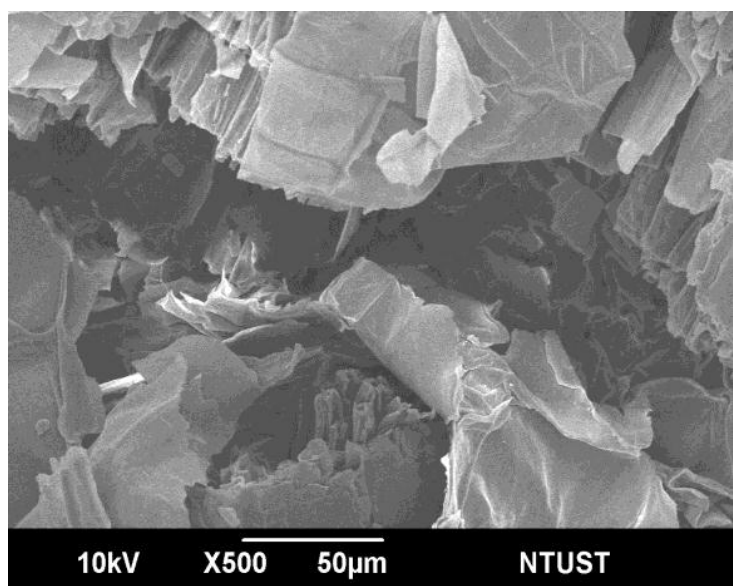

(4C)

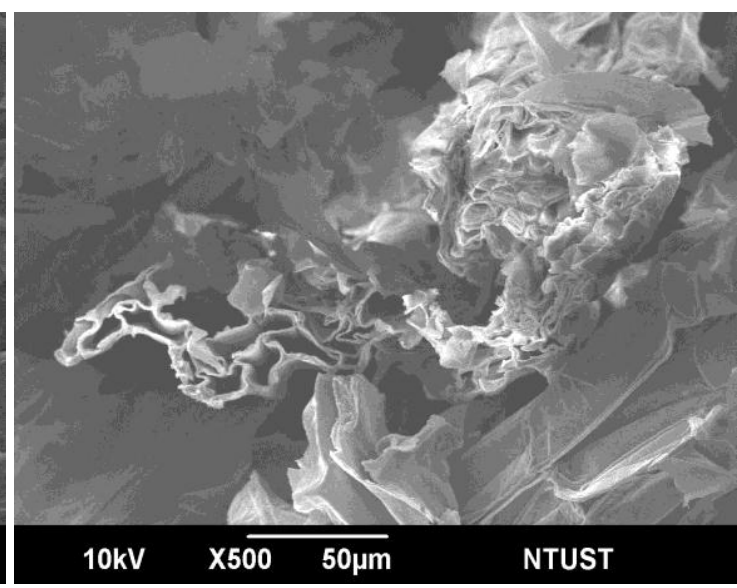

(4B)

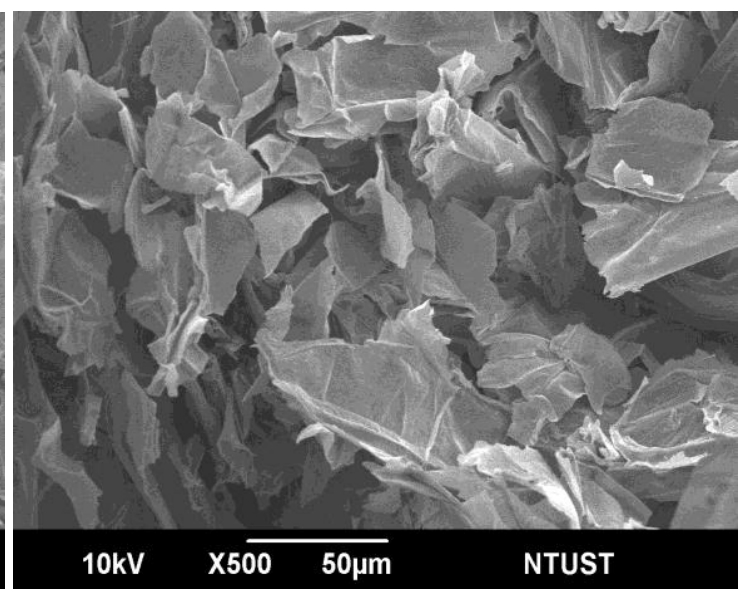

(4D)

Fig. 4. SEM images of water hyacinth. (4A) untreated sample; (4B) treated by ultrasound at $70^{\circ} \mathrm{C}$ for $1 \mathrm{~h}$ with DIW to dried biomass ratio of $10: 1$ (mL/g); (4C) treated by water bath at $100^{\circ} \mathrm{C}$ for $1 \mathrm{~h}$ with DIW to dried biomass ratio of $10: 1(\mathrm{~mL} / \mathrm{g})$; (4D) treated by microwave at $350 \mathrm{~W}$ for 10 min with DIW to dried biomass ratio of $10: 1(\mathrm{~mL} / \mathrm{g})$.

\section{H. Fourier Transform Infrared Spectroscopy (FTIR)}

Fig. 5 shows FTIR spectra of the untreated water hyacinth and the treated samples. The peaks were observed at 1240 and $1346 \mathrm{~cm}^{-1}$ are those of $\mathrm{C}-\mathrm{O}$ stretching of syringyl lignin and $\mathrm{C}-\mathrm{O}-\mathrm{C}$ of hemicellulose oscillation in anomeric region [19]. The peak at $1500 \mathrm{~cm}^{-1}$ indicates the $\mathrm{C}=\mathrm{C}$ stretching of aromatic rings of lignin [20]. These peaks were observed in untreated water hyacinth but in the treated samples were observed weakly. The peaks at $1346 \mathrm{~cm}^{-1}$ and $1500 \mathrm{~cm}^{-1}$ were disappeared in the microwave treated sample, indicating that lignin was removed. This is in agreement with Abral, 2014 [19] and Sundari, 2012 [20]. These observations indicate that microwave treatment removed lignin leading to expelling of cellulose and hemicellulose from tight matrices. Therefore, cellulose and hemicellulose content of the microwave treated sample was higher than that of the untreated sample and the others treated water hyacinth.

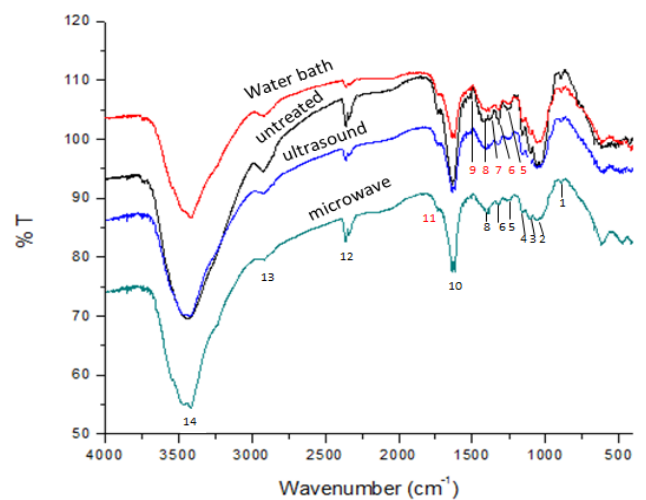

Fig. 5. FTIR spectra of untreated and treated water hyacinth.

\section{CONCLUSION}

Among three pretreatment methods, microwave pretreatment presented the best ability on cellulose and 
hemicellulose recovery. Under conditions of $350 \mathrm{~W}$, DIW to dried biomass ratio $(\mathrm{mL} / \mathrm{g})$ of 10:1 for $10 \mathrm{~min}$, cellulose and hemicellulose recovery was $60.42 \%$ which is $134.18 \%$ of the untreated sample. Morphology and functional groups of all samples were inspected by SEM, TGA and FTIR. Results indicate degradation of lignocellulosic materials which explains the enhancement of cellulose and hemicellulose yield. Based on the results of this study, bioethanol production from water hyacinth will be investigated.

\section{REFERENCES}

[1] M. Y. Harun, A. B. D. Radiah, Z. Z. Abidin, and R. Yunus, "Effect of physical pretreatment on dilute acid hydrolysis of water hyacinth (Eichhornia crassipes)," Bioresource Technology, vol. 102, pp. 5193-5199, 2011.

[2] A. Xia, J. Cheng, W. Song, C. Yu, J. Zhou, and K. Cen, "Enhancing enzymatic saccharification of water hyacinth through microwave heating with dilute acid pretreatment for biomass energy utilization," Energy, vol. 61, pp. 158-166, 2013.

[3] I. N. Ahmed, "Bioethanol production from Melaleuca leucadendron shedding bark: Assessing pretreatments, solid and enzyme loading," Ph.D. thesis, pp. 8-9, 2013.

[4] J. Cheng, R. Lin, W. Song, A. Xia, J. Zhou, and K. Cen, "Enhancement of fermentative hydrogen production from hydrolyzed water hyacinth with activated carbon detoxification and bacteria domestication," International Journal of Hydrogen Energy, vol. 40, pp. 2545-2551, 2015.

[5] J. Yan, Z. Wei, Q. Wang, M. He, S. Li, and C. Irbis, "Bioethanol production from sodium hydroxide/hydrogen peroxide pretreated water hyacinth via simultaneous saccharification and fermentation with a newly isolated thermotolerant Kluyveromyces marxianu strain," Bioresource Technology, vol. 193, pp. 103-109, 2015.

[6] Y. N. Guragain, J. D. Coninck, F. Husson, A. Durand, and S. K. Rakshit, "Comparison of some new pretreatment methods for second generation bioethanol production from wheat straw and water hyacinth," Bioresource Technology, vol. 102, pp. 4416-4424, 2011.

[7] A. Singh and N. R. Bishnoi, "Comparative study of various pretreatment techniques for ethanol production from water hyacinth," Industrial Crops and Products, vol. 44, pp. 283-289, 2013.

[8] U. S. Aswathy, R. K. Sukumaran, G. L. Devi, G. L. Rajasree, R. R. Singhania, and A. Pandey, "Bio-ethanol from water hyacinth biomass: An evaluation of enzymatic saccharification strategy," Bioresource Technology, vol. 101, pp. 925-930, 2010.

[9] J. Gao, L. Chen, Z. Yan, and L. Wang, "Effect of ionic liquid pretreatment on the composition, structure and biogas production of water hyacinth (Eichhornia crassipes)," Bioresource Technology, vol. 132, pp. 361-364, 2013.

[10] F. Ma, N. Yang, C. Xu, H. Yu, J. Wu, and X. Zhang, "Combination of biological pretreatment with mild acid pretreatment for enzymatic hydrolysis and ethanol production from water hyacinth," Bioresource Technology, vol. 101, pp. 9600-9604, 2010.

[11] A. G. Bayrakci and G. Kocar, "Second-generation bioethanol production from water hyacinth and duckweed in Izmir: A case study," Renewable and Sustainable Energy Reviews, vol. 30, pp. 306-316, 2014.

[12] B. J. Khawla, M. Sameh, G. Imen et al., "Potato peel as feedstock for bioethanol production: A comparison of acidic and enzymatic hydrolysis," Industrial Crops and Products, vol. 52, pp. 144-149, 2014.

[13] G. Singh and N. R.Bishnoi, "Ethanol production from pretreated wheat straw hydrolyzate by Saccharomyces cerevisiae via sequential statistical optimization," Industrial Crops and Products, vol. 41, pp. 221-226, 2013.
[14] A. F. Abdel-Fattah and M. A. Abdel-Naby, "Pretreatment and enzymic saccharification of water hyacinth cellulose," Carbohydrate Polymers, vol. 87, pp. 2109-2113, 2012.

[15] D. Ciftci and M. D. A. Saldaña, "Hydrolysis of sweet blue lupin hull using subcritical water technology," Bioresource Technology, vol. 194, pp. 75-82, 2015.

[16] G. L. Miller, "Use of dinitrosalicylic acid reagent for the determination of reducing sugars," Anal Chem, vol. 31, pp. 426-8, 1959.

[17] L. Ge, P. Wang, and H. Mou, "Study on saccharification techniques of seaweed wastes for the transformation of ethanol," Renewable Energy, vol. 36, pp. 84-89, 2011

[18] P. B. Subhedar and P. R. Gogate, "Ultrasound-assisted bioethanol production from waste newspaper," Ultrasonics Sonochemistry, vol. 27, pp. 37-45, 2015 .

[19] H. Abral, D. Kadriadi, and A. Rodianus et al., "Mechanical properties of water hyacinth fibers-polyester composites before and after immersion in water," Materials and Design, vol. 58, pp. 125-129, 2014.

[20] M. T. Sundari and A. Ramesh, "Isolation and characterization of cellulose nanofibers from the aquatic weed water hyacinth-Eichhornia crassipes," Carbohydrate Polymers, vol. 87, pp. $1701-1705,2012$.

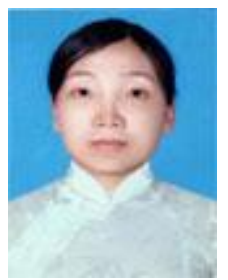

Bich Thuyen Nguyen Thi was born in Vietnam on April 10, 1975. She received her B.Sc. and M.Sc. degrees both in organic chemistry from Can Tho University, Vietnam in 1996 and 2007, respectively. She had experience working in medical company for six years, and then she worked as a lecturer at Can Tho University for eleven years. She is currently working toward her Ph.D. degree at National Taiwan University of Science and Technology, Department of Chemical

Engineering, Taiwan

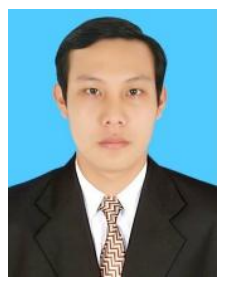

Luong H. V. Thanh received the B.S. degrees from Can Tho University, Cantho, Vietnam, in 2008, and the $\mathrm{Ph}$.D. degree from National Taiwan Uinversity of Science and Technology, Taipei, Taiwan, in 2015. He is currently an assistant professor with Can Tho University, Cantho, Vietnam. His current research interests include separation processes, industrial wastewater treatment and reuse of agricultural by-products.

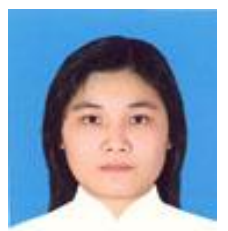

Tran Nguyen Phuong Lan was born in Vietnam, in 1986. She received her PhD degree in the Department of Chemical Engineering, NTUST, Taiwan, in 2015. From August 2015, she has been working as a postdoctoral fellow at the Department of Chemical Engineering, NTUST. Her research interests are focus on biodiesel production, biomass energy, and green chemistry.

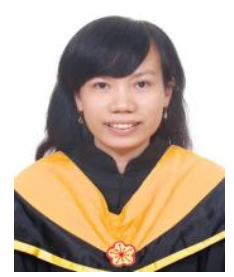

Nguyen Thi Dieu Thuy was born in Quang Binh in Vietnam, on September 25, 1988. She graduated from Can Tho University, Vietnam in 2011 and received her master degree from National Taiwan University of Science and Technology, Taiwan in 2015. Her research interest is renewable energy, biotechnology and nano-technology. 